\title{
The Year in Retrospect
}

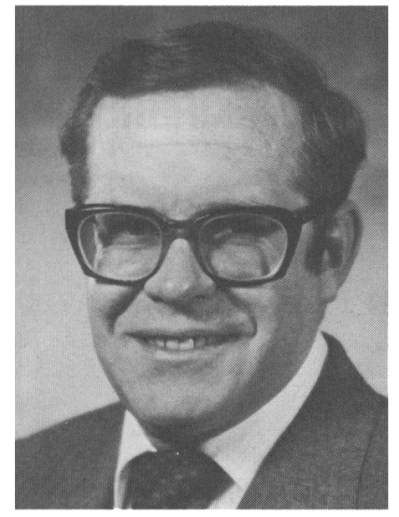

"1984 has seen

MRS become

one of the most

dynamic technical

societies

in the world ..."

\section{W. White, 1984 MRS President}

The year 1984 was a remarkable year for the Materials Research Society and for me personally. During these 12 months, the Society made enormous progress in providing service to the world community of materials research professionals. The activity by the Society this year is unsurpassed in our history, and this has transformed MRS into one of the most dynamic technical societies in the world.

When the year began, I thought that 1984 would be the year in which we would consolidate many of the changes initiated in previous years. This was not to be. Instead, we witnessed the most incredible explosion of participation and activity in our history as a society, and I feel very fortunate to have been a part of this.

To try to put this in some perspective, I will summarize some of our major initiatives and accomplishments this year. Membership in MRS increased by more than $70 \%$ in 1984 , and now stands at approximately 2,400 . Growth of this magnitude is unparalleled in the recent history of technical societies, and this growth should continue throughout 1985 . Corporate support for MRS increased to a record level in 1984. The number of Corporate Affiliates now stands at more than 80 , an increase of almost a factor of two during the year.

We held our first Annual Spring Meeting in Albuquerque, New Mexico, during 1984, and the participation at this meeting was far in excess of our expectations. The Spring Meeting will grow rapidly to become comparable in size and scope to the Fall Meeting in Boston.

Our new Headquarters, established at the end of 1983, was made fully operational this year and has taken responsibility for most of the Society's activities. The ability to centralize our services and activities in the Headquarters office will pay enormous dividends for MRS in future years.

We took over the responsibility for producing and marketing the conference proceedings series and expanded the Headquarters staff in order to do this. Now members and nonmembers can purchase our conference proceedings at the lowest possible prices. We began a major upgrading of the MRS BULLETIN so that it would better serve the needs of MRS members and more efficiently communicate the programs and objectives of the Society to others.

In 1984 our first two Local Sections and two additional Student Chapters were established. These groups will provide greater opportunities for individuals to actively participate in the Society and will provide greater flexibility in the types of programs sponsored by the Society. Furthermore, our colleagues in Europe held the second MRS-Europe meeting in Strasbourg, France, with an attendance of over 400 individuals. A similar interest in MRS style of activity exists in other areas of the world, and MRS regional affiliates in those areas can be expected to develop in future years.
Finally, the 1984 Fall Meeting in Boston was the largest and most successful in our history. Attendance at this meeting exceeded 1,950 scientists and engineers; an increase of more than 400 participants compared to 1983 . The quality of the technical program was the best that we ever had in an MRS meeting, thanks to the Meeting and Symposia Chairpersons. Participation in the meeting by graduate students was at an all-time high, and the number of student awards was increased by $50 \%$ in response to their participation. At the Boston meeting, we initiated two new meeting activities, an MRS Equipment Exhibit and formal Job Placement Center. These activities were organized for us by the American Institute of Physics because MRS is an Affiliated Society of AIP. Both of these activities proved to be highly popular with participants, and will be continued in future years. We also offered a greatly expanded schedule of short courses in the Boston meeting, with over 150 individuals participating in the eight courses. This is four times the number that participated last year, and demonstrates the growing response of the technical community to this MRS endeavor.

The remarkable list of achievements and activities in 1984 was possible only because of very active participation by dozens of people throughout the year. These individuals include the Meeting Chairpersons for the two meetings, the Symposia Chairpersons, the Officers, the Committee Chairpersons, Committee Members, Council Members, and Headquarters Staff. A lot of this activity was initiated and directed by the Society's Committees. Each Committee accomplished its major objectives for the year. This record is personally gratifying, because the vitality of the Society in the future depends completely on the active involvement by these Committees.

I feel very fortunate and proud to have been a part of this. I enjoyed 1984 enormously because of the personal interactions I had with so many people. The Officers, Meeting Chairpersons, Committee Chairpersons, and Council Members with whom I interacted with most frequently are the most qualified, dedicated, and conscientious group of individuals I have ever worked with. I sincerely thank each of them for their patience, help, and guidance throughout the year as they responded to my endless requests for their time. MRS has been made much stronger because of them, and our progress is a reflection of the enterprising spirit with which they worked.

Even though 1984 was indeed an incredible year, 1985 and beyond should be even better. In 1985, MRS will be led by Elton Kaufmann, one of the most capable and dynamic individuals I have ever known. Behind Elton stands a superb group of Officers and Committee Chairpersons. An enormous amount of momentum exists in the Society and the new leaders can be expected to utilize this to further advance the Society's goals. MRS accomplishments in 1985 undoubtedly will be far greater than in 1984 . The next few years are critical to the evolution of the Materials Research Society, and I am certain that the Society's tradition of expanding service will be continued into the future. 